\title{
O QUE COMUNICA E O QUE NÃO COMUNICA: A REITERAÇÃO DO PRECONCEITO LINGUÍSTICO NA MÍDIA ${ }^{1}$
}

Caciane Souza de Medeiros ${ }^{2}$

Resumo: O presente texto desenvolve uma reflexão sobre os conceitos de língua e gramática enunciados em âmbito midiático. A partir do pensamento de Michel Pechêux de que a língua serve para comunicar e para não-comunicar, entendemos que a reiteração do mesmo - a repetição das normas da Língua Portuguesa - está marcada no dizer que a mídia reproduz em seus meios de comunicação e simplifica a questão da língua e dos sujeitos considerados em massa.

Palavras-chave: língua, gramática e mídia.

Contornando os limites que constituem nossa temática de tese, a relação mídia, discurso e poder; e pontuando um lugar de reflexão específico para o Seminário Gramática no Tempo Presente, propomos problematizar a questão do uso da língua na mídia atual em uma perspectiva discursiva. Para dar corpo e materialidade a esse objetivo, recortamos dois pontos de partida que se relacionam como processo marcado pela circulação do conceito de língua e norma que a mídia enuncia em profusão inflacionada (repetição sucessiva) e dirigida a sujeitos considerados em massa.

O primeiro ponto em que nos amparamos, teórico e basilar para nossa reflexão, trata dos princípios gerais da teoria do discurso na referência que faz Michel Pêcheux de que a linguagem serve para comunicar e para não-comunicar. A partir dessa consideração, postulamos a necessidade de explicitar o conceito de língua que se constitui em uma teoria discursiva cunhada por Pechêux (1995).

Pêcheux (1995), no que se refere à língua, trabalha duas noções opositivas: a noção de base lingüística (o próprio sistema lingüístico, enquanto conjunto de estruturas morfossintáticas regido

\footnotetext{
1 Este trabalho é parte do desenvolvimento teórico-metodológico de nossa tese acerca da tríade mídia, discurso e poder, desenvolvida sob a orientação da Prof $^{\mathrm{a}}$ Dr. Amanda Eloina Scherer.

2 Doutoranda em Letras/Estudos Lingüísticos UFSM/PPGL/Laboratório Corpus.
} 
por leis internas) e a noção de processo discursivo-ideológico. Nas palavras do autor:

[...] o sistema da língua é, de fato, o mesmo para o materialista e para o idealista, para o revolucionário e para o reacionário, para aquele que dispõe do conhecimento dado e para aquele que não dispõe desse conhecimento. Entretanto, não se pode concluir, a partir disso, que esses diversos personagens tenham o mesmo discurso: a língua se apresenta, assim, como a base comum dos processos discursivos diferenciados, que estão compreendidos nela na medida em que (...) os processos ideológicos simulam os processos científicos (PẾCHEUX, 1995, p. 91)

Ainda sobre a noção de base lingüística, Pêcheux teoriza nos seguintes termos:

Ao opor base lingüística e processo discursivo, inicialmente estamos pretendendo destacar que [...] todo sistema lingüístico, enquanto conjunto de estruturas fonológicas, morfológicas e sintáticas, é dotado de uma autonomia relativa que o submete a leis internas, as quais constituem, precisamente, o objeto da lingüística. (lbid., p. 91)

A partir dessas considerações, e dando como ponto de partida a noção de base lingüística, Pêcheux desenvolverá a noção de processo discursivo. Segundo ele, é sobre a base que o processo ganha movimento, já que: "É, pois, sobre a base dessas leis internas que se desenvolvem os processos discursivos, e não enquanto expressão de um puro pensamento, de uma pura atividade cognitiva, etc., que utilizaria 'acidentalmente' os sistemas lingüísticos” (Ibid., p. 91).

Assim, o que Pêcheux chama de processo discursivo não é a fala, no sentido de uma manifestação individual (a parole) da língua, mas sim um processo inscrito em uma relação ideológica social dos sujeitos e suas práticas.

É nesse viés, explorado teoricamente por Pechêux, que encontramos orientação para compreender que a língua serve tanto para comunicar quanto para não-comunicar e que a gramática, como lugar do possível, do estável, não se fecha no conceito de língua como instrumento. Na reflexão de Pechêux, a comunicação, em sua relação com a linguagem:

[...] não é "instrumento técnico ou científico" e que essa "comunicação" não é a priori identificável às comunicações 
materiais fornecidas por diversos meios estudados em outros domínios, o que leva a pensar que a expressão "instrumento de comunicação" deve ser tomada em sentido figurado e não em sentido próprio, na medida em que esse "instrumento" permite, ao mesmo tempo, a comunicação e a não-comunicação, isto é, autoriza a divisão sob a aparência da unidade, em razão do fato de não se estar tratando, em primeira instância, da comunicação de um sentido (lbid., p. 92-3).

Neste ínterim, a língua passa a ser vista não apenas como conjunto de convenções formais das quais o sujeito se apropria para significar(-se), mas como condição e possibilidade de constituição de um discurso. Tal concepção de língua resultará em uma transformação na maneira de pensar o sujeito enquanto instância produtora de sentido, negando o sujeito dono de seu dizer, em nível de intencionalidade, para trazer à reflexão o assujeitamento e a interpelação ideológica que constituem o sujeito e se e se mostram na e pela linguagem.

O segundo ponto que nos dispomos a pensar, também pilar de nossa reflexão, em conseqüência do que vimos costurando teoricamente, é a questão do sujeito face à mídia e à profusão de seus meios. Orlandi (2001), ao abordar a relação televisão e memória explicita que, na tevê, "o que mais impressiona é sua capacidade de circulação em meio a uma grande massa heterogênea de sujeitos" (Ibid., p. 179). Os sujeitos na mídia são considerados em massa e, mesmo em sua multiplicidade de meios de expressão audiovisual, a tevê, assim como outros instrumentos midiáticos, produz uma homogeneização de seus fins. Na mídia, há o pressuposto da massificação dos sujeitos e dos dizeres.

Althusser (1988), ao problematizar as teses marxistasleninistas, afirma que são as massas que fazem a história. Dessa forma, no lugar de um sujeito empírico e idealizado (considerado como o sujeito cartesiano) estão as massas, ou seja, as formações sociais heterogêneas e/ou em conflito. Para Althusser, é o conflito, funcionando como motor, que impulsiona o funcionamento histórico, o qual é visto não como sucessão cronológica de eventos de caráter teleológico, mas, sim, como uma cadeia de avanços e retrocessos, rupturas, enfim, são as massas que alavancam a história.

Para movimentar a leitura teórica materialista e pensá-la em suas práticas nos meios de comunicação, trazemos à baila um exemplo de veiculação midiática, em um lugar jornalístico de veiculação com largo alcance físico e sociocultural. Neste exemplo, 
podemos observar que a reiteração do mesmo (Orlandi, 2001) é instada na reprodução de um preconceito socialmente construído: o lingüístico. Observemos transcrição de seqüência de diálogo ${ }^{3}$ entre apresentadores do Jornal do SBT e um comentarista acerca do Acordo Ortográfico da Língua Portuguesa (LP) veiculado neste ano em uma das edições do jornal eletrônico:

(apresentadora/Cynthia Benini) "Brasileiros vão ter que reaprender a escrever.

(apresentadora) Novas regras de ortografia começarão no ano que vem.

(apresentador/Carlos Nascimento) Há muito tempo os países de Língua Portuguesa tentam aí entrar num acordo e unificar a ortografia. Será que dessa vez vai?

(comentarista/Joseval Peixoto) Somos separados de Portugal pela língua, né? Curioso.

São várias as alterações propostas: cai o hífen dobrando-se o 'r' ou o 's' em palavras como ultra-som e contra-regra, por exemplo. Cai o trema sobre palavras como lingüiça, sai o acento circunflexo de certos verbos, também o chamado chapeuzinho de palavras como vôo, enjôo, cai o acento agudo de idéia, assembléia. Também as paroxítonas compostas com 'i' e 'u' em feiúra e, por fim, o alfabeto recepciona oficialmente as letras $\mathrm{k}, \mathrm{w}$ e y que estavam de intrometidas na língua.

O jornalista Ruy Castro diz hoje, na Folha, que afinal poderá escrever seu nome com y sem contestação. É difícil, não é? Mas isso vai estar tudo na internet. Se errar o sistema corrigi. A internet, hoje, mais que as bibliotecas é o grande templo na cultura universal.

(apresentador) É, você também vai poder escrever seu nome com y, agora, oficialmente...

(apresentadora) Com y... eu lembro que quando eu era pequena era difícil. A professora não..., se recusava a botar o y.

(apresentador) Resolveu. Agora, por exemplo, se vai acabar o trema a gente vai falar lingüiça ou linguiça? (risos)

(apresentadora) risos.... Bom, as pessoas já falam muito errado, acho que vão continuar, então, pelo jeito.

Antes de interpretarmos o tema em questão abordado no jornal, o Acordo Ortográfico da LP, atentamos para a explicitação do conceito de gramática no lugar discursivo em que estamos refletindo. A Gramática pode ser considerada como elemento de uma das primeiras revoluções tecnológicas da história do homem (Auroux, 1992). Ela constitui-se na história como uma instrumentação das línguas que, enquanto arte (no sentido latino) ou

Transcrição do material em vídeo disponível em:
http://br.youtube.com/watch?v=9b9E35ZopGg

fragmentum, n. 19. Laboratório Corpus: UFSM, 2008. 
técnica (no sentido grego), apresenta-se como um modo de ensinar a ler e a escrever corretamente. Ou seja, a Gramática instala como central, no domínio dos estudos da linguagem, a qualidade da correção.

O exemplo que trazemos faz referência à questão do Acordo Ortográfico da LP e suas implicações práticas de mudança na escrita e na pronúncia lingüística. No entanto, o que nos chama a atenção são as marcas que se materializam no discurso dos apresentadores e do comentarista do telejornal e que relacionam, ao mesmo tempo, preconceito lingüístico, memória histórica e posições de poder socialmente estabelecidas que se mostram em uma horizontalidade estável e sócio-historicamente determinada (a da norma como senso comum) do que "pode e deve ser dito" (Pechêux, 1995).

O que estamos refletindo está orientado na seguinte questão: de que lugar ou lugares falam os sujeitos veiculadores deste dizer sobre o Acordo? As mudanças ortográficas prevêem obrigatoriamente um reaprender a escrever no sentido idealizado de um começar do zero? Somos separados de Portugal pela língua ou para além dela? E se o sistema corrige tudo, de que reaprender a língua fala o jornalista? Que lugar social metaforiza a internet como o grande templo da cultura universal ao mesmo tempo em que estratifica sujeitos como (in)competentes/errantes na Língua Portuguesa?

Não vislumbramos respostas definitivas para essas questões. Diante da oportunidade de interlocução com o grupo, em especial com os professores Carme Schons ${ }^{4}$ e Luiz Francisco Dias ${ }^{5}$, abrimos espaço para explicitar que em qualquer língua (em suas diferentes manifestações - escrita, oral, em seus modos de normatização), as palavras nascem, morrem, mudam de sentido, reúnem-se e separam-se, são substituídas, cortadas, ampliadas.

A língua, na perspectiva em que nos inscrevemos, não está, no entanto, separada da economia, da tecnologia, da organização da sociedade, dos costumes, da política, dos movimentos sociais e tampouco das revoluções. No entanto, o que interpretamos no dito da mídia sobre a língua e os falantes da mesma é a redução

Professor Doutor da UFMG que proferiu a conferência "A Enunciação do Saber Gramatical: Traços do Passado e Configuração do Presente", no XI Seminário Corpus - A Gramática no Tempo Presente.

${ }^{5}$ Professora Doutor da UPF que foi debatedora no evento supracitado. 
simplista de uma sucessão de pré-conceitos normativos já dados, repetidos, e repetidos... repetidos o suficiente para que se tente anular a memória, colocando-se indiferente aos fatos que reclamam sentidos.

\section{Referências Bibliográficas}

ALTHUSSER, L. Aparelhos Ideológicos do Estado. Rio de Janeiro. Graal, 1982.

AUROUX, S. A Revolução Tecnológica da Gramatização. Campinas, SP: Editora da Unicamp, 1992.

ORLANDI, E. P. Discurso e Texto: Formação e Circulação dos Sentidos. Campinas, SP, Pontes, 2001.

PÊCHEUX, M. Semântica e Discurso: Uma Crítica à Afirmação do Óbvio. Trad. de Eni P. Orlandi. 2 ed. Campinas, SP: Editora da Unicamp, 1995. 